\title{
IMPACTS OF WATER SUPPLY UNCERTAINTY AND STORAGE ON EFFICIENT IRRIGATION TECHNOLOGY ADOPTION
}

\author{
ANIK BHADURI ${ }^{1}$, UTPAL MANNA $^{2}$, AND AHMAD M. MANSCHADI $^{1}$
}

\begin{abstract}
In the framework of a stochastic dynamic programming model, the paper investigates the impact of water supply uncertainty on adoption of efficient irrigation technologies under flexible water price regime. We find that even a flexible water pricing cannot guarantee a higher adoption of efficient irrigation technology in all cases. A risk averse farmer may invest more in efficient irrigation only if the variance in water supply is very high. We also find that if farmers invest in water storage capacity then the value of efficient irrigation increases, and the rate of adoption will be higher. It establishes a complementarity relationship between investment in storage capacity and adoption of efficient irrigation technology. The relationship becomes stronger with increasing variance in water supply.
\end{abstract}

Keywords: Stochastic dynamic programming, water pricing, adoption of efficient irrigation technology.

\section{INTRODUCTION}

Currently, irrigated agriculture occupies 20 per cent of the total arable land in the world and produces more than 40 per cent of the total agricultural production. Irrigation water is becoming an increasingly scarce resource for the agricultural sector in many regions and countries. In the past, water policy schemes relied more on the development of irrigation infrastructures and expansion of irrigated area. However, these expansionary policies are not sufficient to guarantee uninterrupted supply of irrigation water as demand for water continues to increase. Moreover, the likelihood of additional irrigation projects is

\footnotetext{
${ }^{1}$ Center for Development Research (ZEF), University of Bonn, Germany.

${ }^{2}$ School of Mathematics, Indian Institute Of Science Education and Research, Thiruvananthapuram, India.

Corresponding e-mail addresses: abhaduri@uni-bonn.de.
} 
questionable, given mounting concerns over the adverse effects of large dams projects, and loss of land to salinization ( [10], [14], [16]).

There is also broad agreement that global climate change may stand to further exacerbate the pressure on hydrological systems with increasing water demand $[1,11]$. The intensity and frequency of floods and droughts are also expected to change. Coping with the effects of climate change on water will require demand management measures to enhance the efficient usage of water [7]. In the agricultural sector, which typically uses up to 70 percent of water resources, conservation and efficient usage will be critical to sustainable water management and climate change adaptation. The use of modern irrigation technologies has been proposed as one of several possible solutions to the problem of water scarcity and environmental degradation in many agricultural areas around the world. Seckler et. al (1998) estimate that improvements in irrigation efficiency alone may meet half of the projected increase in water demand by 2025 [4].

Water pricing is one of the options to reduce water use and achieve higher irrigation efficiency. It is often argued that water pricing could promote water use flexibility and establish a recognized water value, and thus provide incentives for more efficient water use [3]. Shah et. al (1995) argued that it may be optimal to increase water price to encourage quicker adoption of water conservation technologies [6]. On the other hand, Carey and Zilberman(2002) found that water markets can delay the adoption of modern irrigation technologies for farms with scarce water supplies [8]. They predicted that farms will not invest in modern technologies unless the expected present value of investment exceeds the cost by potentially large hurdle rate. Ranjan and Athalye (2009) also found water pricing to be least important in influencing adoption of new technologies if it does not capture the true opportunity cost of water [15].

This paper investigates the impact of water supply uncertainty on adoption of efficient irrigation technologies under a flexible water price regime, where the water price depends on excess demand of water. We raise whether such water pricing alone can guarantee the adoption of efficient irrigation technologies, given uncertainty in water supply stemming from climate change. We also investigate if investment in water storage capacity could induce farmers to adopt efficient technology under variable water supply. 
There is substantial literature on stochastic water resource management. Fisher and Rubio (1997) studied the determination of optimal water storage capacity taking into account the flow into water reserves as uncertain, and found that building of the reservoir capacity will become more costly with climate change [2]. Other literature is concerned mainly with the impact of stochastic surface water flows on the value of additional stock of water in either surface reservoir or groundwater aquifers $[18,9]$. However, there is limited literature on the influence of stochastic water resource on the investment in efficient irrigation technologies.

In the framework of a stochastic dynamic programming model, the paper attempts to explore if farmers will adopt efficient irrigation technologies under condition of increasing variance in water supply; and also how the farmer's behaviour changes given the opportunity to invest in water storage capacity.

Following Fisher and Rubio's model, we assume that water resources evolve through time and follow geometric brownian motion [2]. We derive the steady state conditions of the corresponding stochastic problem with respect to optimal investment in efficient irrigation technologies and water storage capacity. We evaluate how these steady state conditions will be modified by changes in the variance of water supply. Our results indicate a negative relationship between the aggregate investment in efficient irrigation and variance, a measure of the uncertainty that is likely to increase with climate change. The negative relationship holds if the marginal benefit function of water consumption is convex or a reduction in water consumption has a larger impact on benefit around the equilibrium. Our results indicate that water pricing cannot guarantee higher adoption of efficient irrigation techniques with increasing variance in water supply. However, the negative impact of uncertainty on investment in efficient irrigation technologies will be less under flexible water pricing. We also explore if there exists complementarity between investment in efficient irrigation and water storage capacity. Water storage increases the resilience against fluctuation in water supply. Moreover, if there is an opportunity to invest in water storage capacity, then the farmers will be motivated to save water. Consequently, the relationship between aggregate investment in efficient irrigation techniques and uncertainty in water supply might be positive. 
The structure of the paper is as follows. In the next section, we outline the model assumptions and determine the optimal investment in irrigation technology under uncertainty. In the third section, we reformulate the model with the option of a water storage reservoir. In section four we present the numerical analysis results. Finally the conclusion section summarizes the main findings and results of the paper.

\section{Model}

In the present section, we structure a farm-based model, where a farmer is assumed to maximize an instantaneous profit function by choosing the amount of water to apply to its crops and the area of land to be irrigated with efficient irrigation technologies. Suppose there are two types of irrigation technology-conventional irrigation( Furrow) and efficient irrigation technology (Sprinkler or drip). The technologies are denoted as $F$ and $H$ for conventional and efficient irrigation technologies. For each irrigation technology $m$, irrigation effectiveness is denoted by $e_{m}$ where $(m=F, H)$ and $1>e_{H}>e_{F}>0$. Suppose the area covered under effective technology at time $t$ is $H(t)$. The rate of change in area covered with efficient irrigation technology can be shown as

$$
\dot{H}=h-\delta_{H}(H)
$$

where $H(t=0)=H_{0}$ and $h$ is the amount of new area brought under new irrigation technology. $\delta_{H}$ represents the depreciation rate of new technology. Consider the total applied irrigation water (gross) as $w$. The net effective water applied for farm $i$ can be represented as

$$
w_{e}=w\left[e_{F}(1-H)+e_{H} H\right]
$$

where the area of land has been normalized as one hectare and thus the aggregate area of efficient irrigation area $(\mathrm{H})$ is less than one ${ }^{1}$.

Consider benefit $B\left(w_{e}\right)$ as a function of effective water, $w_{e}$. We assume the benefit function of water is concave in $w_{e}$ with $B_{w_{e}}>0$ and $B_{w_{e} w_{e}}<0$. Again we assume that the marginal cost of efficient irrigation is constant, and is denoted by $c^{H}$. We consider water flow, $W$, to be stochastic and following geometric Brownian motion

$$
\mathrm{d} W=\sigma W \mathrm{~d} z
$$

\footnotetext{
${ }^{1}$ We have normalized the area of land for analytical simplicity.
} 
where $z$ is a standard Wiener process and $\sigma W$ is the variance rate in the water flow ${ }^{2}$.

The price of water is denoted by $p$. The price of the water evolves over time and is a function of the aggregate excess demand of water,

$$
d p / d t=k\left(\sum w-W\right)
$$

where $k$ is a constant. The net benefit function of water can be represented consecutively as follows

$$
N B_{t}=B\left(w_{e}\right)-c^{H} h-p w .
$$

Our problem is to choose $w$ and $h$ in order to maximize the expected present value of the net benefit

$$
J(H, p, W)=\max _{\{w, h\}} E \int_{0}^{\infty} N B_{t} e^{-r t} d t .
$$

The corresponding Bellman equation can be written as

$$
r J=\max _{\{w, h\}}\left[B\left(w_{e}\right)-c^{H} h-p w+1 / d t E_{t}(d J)\right] .
$$

Since $W$ is a stochastic process we can use Itô's lemma to write

$$
d J=J_{H} d H+J_{p} d p+J_{W} d W+(1 / 2) J_{W W}(d W)^{2},
$$

and by substituting $d H, d p, d W$ and $(d W)^{2}$ we obtain,

$d J=J_{H}\left(h-\delta_{H} H\right) d t+J_{p} k\left(\sum w-W\right) d t+J_{W} \sigma W d z+(1 / 2) J_{W W} \sigma^{2} W^{2} d t$.

Applying the differential operator $\frac{1}{d t} E_{t}$ and considering that $E_{t}(d z)=0$, again from the definition of a Wiener process, equation (2.8) can be written as

$$
(1 / d t) E_{t}(d J)=J_{H}\left(h-\delta_{H} H\right)+J_{p} k\left(\sum w-W\right)+(1 / 2) \sigma^{2} W^{2} J_{W W} .
$$

Hence the Bellman equation can be rewritten as

$$
\begin{aligned}
& r J=\max _{\{w, h\}}\left[B\left(w_{e}\right)-c^{H} h-p w+J_{H}\left(h-\delta_{H} H\right)+J_{p} k\left(\sum w-W\right)\right. \\
& \left.+(1 / 2) \sigma^{2} W^{2} J_{W W}\right] .
\end{aligned}
$$

Maximizing the above equation with respect to $w$ and $h$, we get the following first order conditions

\footnotetext{
${ }^{2}$ From a hydrological perspective, the contribution of drift component in the total change of water flow is negligible [2]. Hence, we have excluded the deterministic drift component
} 


$$
\frac{\partial B}{\partial w_{e}} \frac{\partial w_{e}}{\partial w}-p+k J_{p}=0, \quad-c^{H}+J_{H}=0 .
$$

The above equation suggests that at the margin, the marginal benefit of water equals the marginal cost of water. The marginal cost of water includes the price of water $(p)$ and the scarcity value of water reflected in the change in the price of water $\left(J_{p}\right)$.

Also, the marginal value of efficient irrigation, given by $J_{H}$, is equal to the price used to value increments to capital stock, $c^{H}$. The price of adopting efficient irrigation represents the opportunity cost of the investment.

Differentiating the Bellman equation (2.10) with respect to the state variable $p$ and given the optimal values of the control variables $w$ and $h$, we obtain

$$
\begin{aligned}
r J_{p}= & \left(B_{w}-p+k J_{p}\right) \frac{\partial w}{\partial p}-\left(c^{H}-J_{H}\right) \frac{\partial h}{\partial p}-w+\left(h-\delta_{H} H\right) J_{H p} \\
& +k\left(\sum w-W\right) J_{p p}+(1 / 2) \sigma^{2} W^{2} J_{W W p} .
\end{aligned}
$$

Note that the first two terms in parentheses of the above equation are zero given the first order conditions (2.11). Hence

$$
r J_{p}=-w+\left(h-\delta_{H} H\right) J_{H p}+k\left(\sum w-W\right) J_{p p}+(1 / 2) \sigma^{2} W^{2} J_{W W p} .
$$

Using Itô's lemma we have

$$
\begin{aligned}
d J_{p}= & J_{H p}\left(h-\delta_{H} H\right) d t+J_{p p} k\left(\sum w-W\right) d t+J_{W p}(\sigma W d z) \\
& +(1 / 2) J_{W W p} \sigma^{2} W^{2} d t .
\end{aligned}
$$

Applying the differential operator $(1 / d t) E_{t}$ to the above equation, and considering that $E_{t}(d z)=0$, we obtain

$$
(1 / d t) E_{t} d J_{p}=J_{H p}\left(h-\delta_{H} H\right)+J_{p p} k\left(\sum w-W\right)+(1 / 2) J_{W W p} \sigma^{2} W^{2} .
$$

Substituting (2.15) in (2.13),

$$
r J_{p}+w=\frac{1}{d t} E\left(d J_{p}\right) .
$$

From Appendix A, we know

$$
w+r J_{p}=\frac{1}{2 k}\left(p_{w w}-B_{w w w}\right)\left(\frac{\partial w}{\partial W}\right)^{2} \sigma^{2} W^{2} .
$$


After substituting $J_{p}=\frac{1}{k}\left[p-\frac{\partial B}{\partial w}\right]$ from first order condition (2.11) and $P_{w w}=0$, the above expression $(2.17)$ can be written as ${ }^{3}$

$$
r B_{w}=k w+r p+\frac{1}{2}\left(B_{w w w}\right)\left(\frac{\partial w}{\partial W}\right)^{2} \sigma^{2} W^{2} .
$$

The above equation (2.18) implies that at equilibrium the marginal benefit of water consumption equals the marginal cost where the latter also includes a term related to instantaneous rate of variance in water supply.

Now differentiating the Bellman equation (2.10) with respect to the state variable $H$, for the optimal values of the control variables $w$ and $h$,we get

$$
\begin{aligned}
r J_{H}= & \left(B_{w}-p+J_{p}\right) \frac{\partial w}{\partial H}-\left(c^{H}-J_{H}\right) \frac{\partial h}{\partial H}+B_{w_{e}} \frac{\partial w}{\partial H}-\delta_{H} J_{H}+\left(h-\delta_{H} H\right) J_{H H} \\
& +k\left(\sum w-W\right) J_{p H}+(1 / 2) \sigma^{2} W^{2} J_{W W H} .
\end{aligned}
$$

As the first two terms in parentheses of the above equation are zero from the first order conditions $(2.11)$ and $1 / d t E_{t}\left(d J_{H}\right)=\left(h-\delta_{H} H\right) J_{H H}+$ $k\left(\sum w-W\right) J_{p H}+(1 / 2) \sigma^{2} W^{2} J_{W W H}$, we have

$$
1 / d t E_{t}\left(d J_{H}\right)=\left(r+\delta_{H}\right) c^{H}-B_{w_{e}} \frac{\partial w_{e}}{\partial H} .
$$

Substituting $J_{H}=c^{H}$ in (2.20)and setting $d c^{H}=0$, we get

$$
\left(r+\delta_{H}\right) c^{H}=B_{w_{e}} w\left(e_{H}-e_{F}\right)
$$

The above equation (2.21) implies that at equilibrium the benefit of increasing aggregate investment in efficient irrigation is equal to opportunity cost of capital $\left(r+\delta_{H}\right) c^{H}$.

Now, substituting $w=\frac{\left(r+\delta_{H}\right) c^{H}}{B_{w_{e}}\left(e_{H}-e_{F}\right)}$ from (2.21)and differentiating equation (2.17),

$$
-\frac{B_{w_{e} w_{e}}\left(r+\delta_{H}\right) c^{H} w}{B_{w_{e}}{ }^{2}} d H+r \frac{\partial\left(J_{p}\right)}{\partial H} d H=-\frac{1}{2 k}\left(B_{w w w}\right)\left(\frac{\partial w}{\partial W}\right)^{2} W^{2} d\left(\sigma^{2}\right)
$$

where

$$
\frac{\partial J_{p}}{\partial H}=\frac{1}{k}\left[p_{w_{e}} w-B_{w_{e} w_{e}} w_{e}-B_{w_{e}}\right]\left(e_{H}-e_{F}\right) .
$$

\footnotetext{
${ }^{3}$ Considering a linear price function of water, we have $P_{w w}=0$
} 
Now rearranging the above equation,

$$
\frac{d H}{d\left(\sigma^{2}\right)}=-\frac{\frac{1}{2 k}\left(B_{w w w}\right)\left(\frac{\partial w}{\partial W}\right)^{2} W^{2}}{r \frac{\partial J_{p}}{\partial H}-\frac{B_{w_{e} w_{e}}\left(r+\delta_{H}\right) c^{H} w}{\left[B_{w_{e}}\right]^{2}}} .
$$

We found the denominator of the above fraction is positive (see Appendix $\mathrm{B}$ ). The numerator is negative only if the marginal benefit of water consumption is convex which means $B_{w w w}>0$. In that case, we found $\frac{d H}{d\left(\sigma^{2}\right)}<0$ indicating a negative relationship between aggregate investment in efficient irrigation and variance in water supply. It suggests that if the marginal benefit is convex $\left(B_{w w w}>0\right)$, then around the equilibrium a reduction in consumption has a larger impact than an increase in benefit; and hence relationship between investment in efficient irrigation and variance in water supply will be negative. Under such circumstances, farmers may buy more water rather than investing in efficient irrigation techniques. Hence, presence of flexible water price cannot guarantee an increase in the adoption rate of efficient irrigation technology under increasing uncertainty in water supply ${ }^{4}$.

However if the marginal benefit function is concave $\left(B_{w w w}<0\right)$, then a reduction in water consumption will have a smaller impact on benefit. Hence the farmer will invest more in efficient irrigation with increase in uncertainty in water supply and $\frac{d H}{d\left(\sigma^{2}\right)}>0$.

\section{INVESTMENT IN EFFICIENT IRRIGATION AND WATER STORAGE}

In this section, we evaluate how investment in efficient irrigation will change with variance in water flow if there is an opportunity to invest in water storage. We explore if storage water will increase the resilience of the farmers against the effects of uncertainty in water flow on benefits.

We assume that the farmer will buy water and use $\beta$ proportion of water while storing $(1-\beta)$ proportion of water. The water constraint $(\mathrm{A}-2)$ can be rewritten as

$$
w_{e}=\beta w\left[e_{F}(1-H)+e_{H} H\right]
$$

The stock of water denoted by $S$ can be expressed as

$$
\dot{S}=(1-\beta) w, \text { if } S<\alpha K \text {. }
$$

\footnotetext{
${ }^{4}$ Under flexible water price regime $p_{w_{e}}>0$ and $\frac{\partial J_{p}}{\partial H}$ will be more positive compared to the case of fixed water price where $p_{w_{e}}=0$. As a result $\frac{d H}{d\left(\sigma^{2}\right)}$ will be less negative under flexible water price.
} 
Otherwise

$$
\dot{S}=\min [0,(1-\beta) w], \text { if } S=\alpha K
$$

where $\alpha$ is a conversion factor that gives storage capacity as a function of the capital stock. The capital stock $K$ evolves over time according to

$$
\dot{K}=I-\delta_{K} K
$$

where $I$ is investment and $\delta_{K}$ is the rate of depreciation.

The Net benefit can be rewritten as

$$
N B_{t}=B\left(w_{e}\right)-c^{H} h-c^{K} \cdot I-p w .
$$

where $c^{K}$ is the cost of investment.

The Bellman equation can be rewritten as

$$
\begin{array}{r}
r J=\max _{\{w, h, I\}}\left[B\left(w_{e}\right)-c^{H} h-c^{K} . I-p w+J_{H}\left(h-\delta_{H} H\right)+J_{K}\left(h-\delta_{K} K\right)\right. \\
\left.+J_{p} k\left(\sum w-W\right)+J_{s}((1-\beta) w)+\psi(\alpha K-S)+(1 / 2) \sigma^{2} W^{2} J_{W W}\right]
\end{array}
$$

where $\psi$ is the multiplier associated with the restriction $S \leq \alpha K$; $\psi$ is positive if $S=\alpha K$, and zero otherwise.

We will maximize the above equation with respect to $w, h$ and $I$. The first order conditions can be written as

$$
\begin{aligned}
& \frac{\partial B}{\partial w_{e}} \frac{\partial w_{e}}{\partial w}-p+k J_{p}+(1-\beta) J_{S}=0, \\
& -c^{H}+J_{H}=0 \\
& -c^{K}+J_{S}=0
\end{aligned}
$$

The first order condition (3.31) suggests that marginal value of water for consumption, given by the marginal benefit function, is equal to marginal cost of water. The marginal cost includes price of water, the scarcity value of water reflected by the change in the price of water $\left(J_{p}\right)$ and marginal value of storage of water. Also the other first order conditions suggest that for investment, the marginal value of capital in efficient irrigation and for storage capacity, as given by $J_{H}$ and $J_{K}$, is equal to the price used to value increments to their stock, $c^{H}$ and $c^{K}$, respectively. 
Similarly as in section 2, differentiating the Bellman equation (3.30) with respect to the state variable $p$, results in

$$
\frac{1}{d t} E\left(d J_{p}\right)=r J_{p}+w
$$

Again, differentiating the Bellman equation (3.30) with respect to the state variable $S$, for the optimal values of the control variables $w, h$ and $I$, we have

$$
\begin{aligned}
r J_{S}= & \left(B_{w}-p+k J_{p}+(1-\beta) J_{S}\right) \frac{\partial w}{\partial S}-\left(c^{H}-J_{H}\right) \frac{\partial h}{\partial S}-\left(c^{K}-J_{K}\right) \frac{\partial I}{\partial S} \\
& -\psi+\left(h-\delta_{H} H\right) J_{H S}+k\left(\sum w-W\right) J_{p S}+((1-\beta) w) J_{S S} \\
& +\left(I-\delta_{K} K\right] J_{K S}+(1 / 2) \sigma^{2} W^{2} J_{W W S} .
\end{aligned}
$$

Note that the first three terms in the parentheses are zero. Hence

$$
\begin{aligned}
r J_{S}= & -\psi+\left(h-\delta_{H} H\right) J_{H S}+k\left(\sum w-W\right) J_{p S} \\
& +((1-\beta) w) J_{S S}+\left(I-\delta_{K} K\right] J_{K S}+(1 / 2) \sigma^{2} W^{2} J_{W W S} .
\end{aligned}
$$

Now using Ito's Lemma we have

$$
\begin{aligned}
d J_{S}= & J_{H S}\left(h-\delta_{H} H\right) d t+J_{p S} k\left(\sum w-W\right) d t+J_{S S}((1-\beta) w) d t+J_{K S}\left(I-\delta_{K} K\right) d t \\
& +J_{W p}(\sigma W d z)+(1 / 2) J_{W W S} \sigma^{2} W^{2} d t .
\end{aligned}
$$

Applying the differential operator $(1 / d t) E_{t}$ to the above equation, and considering that $E_{t}(d z)=0$, we obtain

$$
\begin{aligned}
\frac{1}{d t} E\left(d J_{S}\right)= & J_{H S}\left(h-\delta_{H} H\right)+J_{p S} k\left(\sum w-W\right)+J_{S S}((1-\beta) w)+J_{K S}\left(I-\delta_{K} K\right) \\
& +(1 / 2) J_{W W S} \sigma^{2} W^{2} .
\end{aligned}
$$

Substituting (3.38) in (3.36), we obtain

$$
\frac{1}{d t} E\left(d J_{S}\right)=r J_{S}+\psi
$$

Now differentiating the Bellman equation (3.30) with respect to the state variable $K$, for the optimal values of the control variables $w, I$ and $h$, we have

$$
\begin{aligned}
r J_{K}= & \left(B_{w}-p+k J_{p}+(1-\beta) J_{S}\right) \frac{\partial w}{\partial K}-\left(c^{H}-J_{H}\right) \frac{\partial h}{\partial K}-\left(c^{K}-J_{K}\right) \frac{\partial I}{\partial K} \\
& +\psi \alpha-\delta_{K} J_{K}+\left(h-\delta_{H} H\right) J_{I K}+k\left(\sum w-W\right) J_{p K}+((1-\beta) w) J_{S K} \\
& +\left(I-\delta_{K} K\right] J_{K K}+(1 / 2) \sigma^{2} W^{2} J_{W W K} .
\end{aligned}
$$


As the first three terms in the parentheses are zero from the first order conditions (3.31) and $1 / d t E_{t}\left(d J_{K}\right)=\left(\left(h-\delta_{H} H\right) J_{I K}+k\left(\sum w-W\right) J_{p K}+\right.$ $((1-\beta) w) J_{S K}+\left(I-\delta_{K} K\right) J_{K K}+(1 / 2) \sigma^{2} W^{2} J_{W W K}$, we obtain.

$$
1 / d t E_{t}\left(d J_{K}\right)=\left(r+\delta_{K}\right) c^{K}+\psi \alpha
$$

Substituting $J_{K}=c^{K}$ in (3.41)and setting $d c^{K}=0$, we have

$$
\psi=\frac{1}{\alpha}\left[r+\delta_{K}\right] c^{K}
$$

From Appendix C, we know

$$
r\left(p-B_{w}\right)+k w+(1-\beta) \psi=-\frac{1}{2}\left(B_{w w w}\right)\left(\frac{\partial w}{\partial W}\right)^{2} \sigma^{2} W^{2}
$$

Now, substituting $w=\frac{\left(r+\delta_{H}\right) c^{H}}{B_{w_{e}}\left(e_{H}-e_{F}\right)}($ From $(2.21))$ and $\psi=\frac{1}{\alpha}\left[r+\delta_{K}\right] c^{K}($ From $(3.42))$ in (3.43) and differentiating the latter equation, we obtain

$$
\begin{aligned}
-\frac{1}{2 k}\left(B_{w w w}\right)\left(\frac{\partial w}{\partial W}\right)^{2} W^{2} d\left(\sigma^{2}\right)=\frac{r}{k}[ & {\left[p_{w_{e}} w-B_{w_{e} w_{e}} w_{e}-B_{w_{e}}\right]\left(e_{H}-e_{F}\right) } \\
& \left.-\frac{B_{w_{e} w_{e}}\left(r+\delta_{H}\right) c^{H} w}{\left[B_{w_{e}}\right]^{2}}\right] d H- \\
& \frac{1}{k}\left(B_{w w w}\right)\left(\frac{\partial w}{\partial W}\right) \frac{\partial^{2} w}{\partial W \partial K} \sigma^{2} W^{2} d K .
\end{aligned}
$$

Rearranging the terms in the above equation, we obtain

$$
\begin{aligned}
& \frac{d K}{d\left(\sigma^{2}\right)}= \\
& \frac{-\frac{1}{2 k}\left(B_{w w w}\right)\left(\frac{\partial w}{\partial W}\right)^{2} W^{2}-\left[\frac{r}{k}\left[p_{w_{e}} w-B_{w_{e} w_{e}} w_{e}-B_{w_{e}}\right]\left(e_{H}-e_{F}\right)-\frac{B_{w_{e} w_{e}}\left(r+\delta_{H}\right) c^{H} w}{\left[B_{w_{e}}\right]^{2}}\right] \frac{d H}{d\left(\sigma^{2}\right)}}{\frac{1}{k}\left(B_{w w w}\right)\left(\frac{\partial w}{\partial W}\right) \frac{\partial^{2} w}{\partial W \partial K} \sigma^{2} W^{2}}
\end{aligned}
$$

As storage water will weaken the relationship between changes in $w$ and $W$, the term $\frac{\partial^{2} w}{\partial W \partial K}$ will be negative. Given that the marginal benefit function of water is convex, $\left(B_{w w w}>0\right)$, the denominator of the above fraction becomes negative. The numerator is always negative as the negative first term will dominate the second term because of larger weight $W^{2}$. So regardless of the sign $\frac{d H}{d\left(\sigma^{2}\right)}, \frac{d K}{d\left(\sigma^{2}\right)}$ will be positive 
if $B_{w w w}>0$.On the other hand if the marginal benefit function is concave, $\left(B_{w w w}<0\right)$ and if the reduction in water has a lesser impact on benefit, then also $\frac{d K}{d\left(\sigma^{2}\right)}>0$. However, in this case the change in $k$ from an increase in variance in water supply will be less than the case when the marginal benefit function is convex.

Rearranging equation (3.44), we can derive a relationship between investment in storage reservoir and efficient irrigation technology.

$$
\frac{d H}{d K}=-\frac{\frac{1}{k}\left(B_{w w w}\right)\left(\frac{\partial w}{\partial W}\right) \frac{\partial^{2} w}{\partial W \partial K} \sigma^{2} W^{2}}{\frac{r}{k}\left[p_{w_{e}} w-B_{w_{e} w_{e}} w_{e}-B_{w_{e}}\right]\left(e_{H}-e_{F}\right)-\frac{B_{w_{e} w_{e}}\left(r+\delta_{H}\right) c^{H} w}{\left[B_{w_{e}}\right]^{2}}}
$$

In the above function, the denominator is positive(see Appendix B). If $\frac{\partial^{2} w}{\partial W \partial K}<0$, then the sign of $\frac{d H}{d K}$ will depend again on the curvature of the marginal benefit function of water. If the marginal benefit function of water is convex, $B_{w w w}>0$, we find a positive sign of $\frac{d H}{d K}$ which suggests that there exists a complementary relationship between the investment in efficient irrigation and water storage.The relationship also becomes stronger with increasing variance $\frac{d^{2} H}{d K d \sigma^{2}}>0$. Hence if the marginal benefit function is convex, then water storage will give an opportunity to the farmers to save more water, and increasing variance of water supply can induce the farmers to invest more in efficient irrigation. On the other hand, if the marginal benefit function of water is concave, $B_{w w w}<0$ and the reduction in water has a lower effect on benefit, we find a substitutable relationship $\left(\frac{d H}{d K}<0\right)$ between investment in efficient irrigation and reservoir respectively. However, the relationship becomes weaker with increase in variance of water supply as $\frac{d^{2} H}{d K d \sigma^{2}}$ will be negative provided $\frac{\partial^{2} w}{\partial W \partial K}<0$.

\section{Numerical AnAlysis}

In this section, with the help of numerical analysis, we try to evaluate how farmers will invest in efficient irrigation technologies under different levels of uncertainty in water supply. Also we examine the role of flexible water price in the adoption of efficient irrigation.

The baseline parameter values, shown in Table 1, are intended to be representative of actual values. In the numerical analysis we have assumed that the instantaneous utility function of the farmer faces constant relative risk aversion $B\left(w_{e}\right)=P_{A}\left(\frac{w_{e}^{(1-\theta)}}{1-\theta}\right)$, where $\theta$ is the degree 


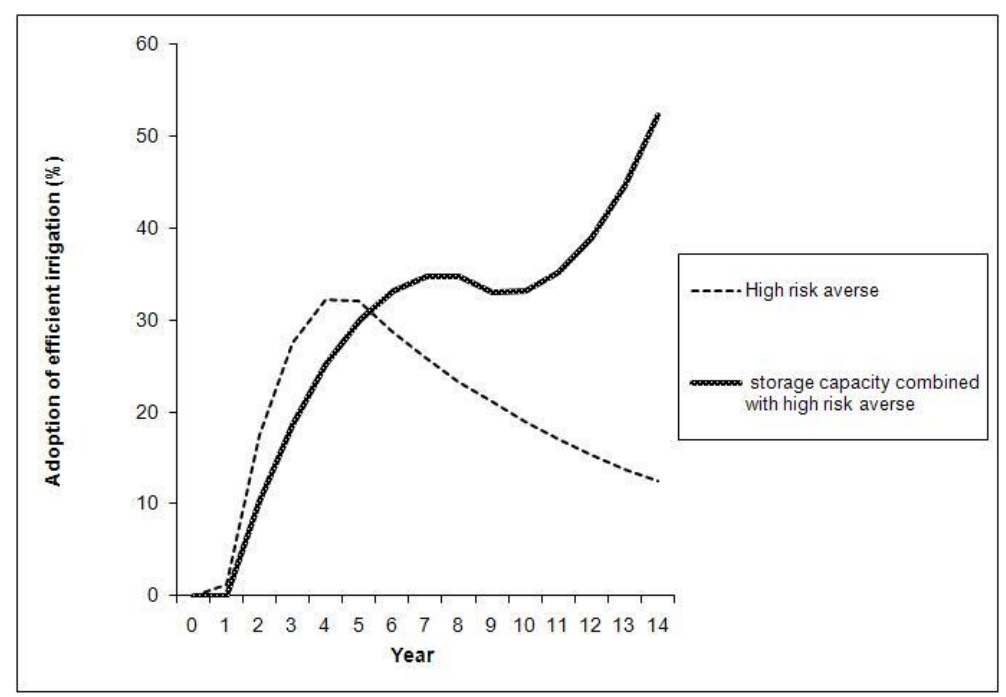

FigURE 1. Adoption of efficient irrigation technology

of risk aversion, and $1 / \theta$ is the intertemporal substitution elasticity between consumption of water in any two periods. The latter measures the willingness to substitute water consumption between different periods. The smaller $\theta$ (the larger $1 / \theta$ ), the more willing is the farmer to substitute water consumption over time.

The results in Figure 1 suggest that a relatively risk averse farmer, with a degree of risk aversion of 0.4 , will invest in efficient irrigation technologies up to 32 per cent of the total area. But if the same farmer also has the opportunity to invest in storage capacity, then the expected benefit from using efficient irrigation technologies increases and the adoption of irrigation technology will reach 52 percent $^{5}$. However, in the initial years the rate of adoption of efficient irrigation will be lower due to investment in storage capacity, and afterwards it will increase at a faster rate.

Figure 2 compares the rate of adoption of efficient irrigation techniques under flexible and fixed water pricing schemes. We found that a flexible price of water plays a significant role in inducing the adoption of efficient irrigation techniques. If the price of water is fixed, then

\footnotetext{
${ }^{5}$ Here the aggregate adoption of efficient irrigation will decrease if the existing irrigation technology is depreciating and the representative farmer is no longer making new investments in irrigation technology.
} 


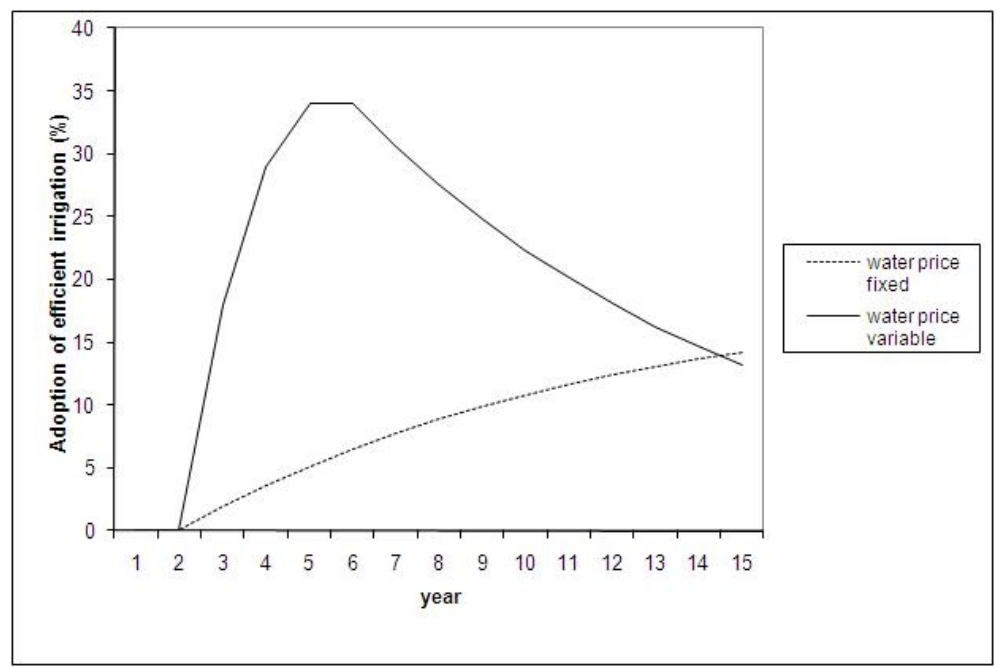

Figure 2. Adoption of efficient irrigation technologies under fixed and flexible water pricing schemes

the rate of adoption is much slower and the aggregate adoption of efficient irrigation techniques will be lower compared to that under flexible water pricing scheme. 
Table 1. Parameters for Numerical Analysis

\begin{tabular}{|c|c|}
\hline parameters & values \\
\hline Depreciation rate $(\delta)$ per year & 0.1 \\
\hline Cost of Investment in irrigation technology(sprinkler) (dollars) per ha $\left(c^{H}\right)$ & 973 \\
\hline Price of water (dollars) 1000 cubic meter & 50 \\
\hline Discount rate & 0.1 \\
\hline Efficiency of Furrow Irrigation $\left(e_{F}\right)$ & 0.55 \\
\hline Efficiency of Sprinkler Irrigation $\left(e_{H}\right)$ & 0.8 \\
\hline Cost of storage water (dollars)per 1000 cubic meter $\left(c^{K}\right)$ & 400 \\
\hline Proportion of water consumed $(\beta)$ & 0.8 \\
\hline Net Benefit (NB) in (dollars) & $\pi=B\left(w_{e}\right)-c^{H} h-c^{K} . I-p w$ \\
\hline $\begin{array}{c}\text { Benefit from water }\left(B\left(w_{e}\right)\right) \\
P_{A} \\
\theta \\
\text { H(Area covered under efficient irrigation technology) }\end{array}$ & $\begin{array}{c}B\left(w_{e}\right)=P_{A}\left(\frac{w_{e}^{(1-\theta)}}{1-\theta}\right) \\
w_{e}=\beta w\left[e_{F}(1-H)+e_{H} H\right] \\
\text { Price of agricultural crops } \\
\text { Constant relative risk aversion parameter } \\
\dot{H}=h-\delta_{H}(H)\end{array}$ \\
\hline K (Capital stock for storage reservoir) & $\dot{K}=I-\delta_{K} K$ \\
\hline $\mathrm{p}$ (price of water) & $d p / d t=k\left(\sum w-W\right)$ \\
\hline $\begin{array}{c}\mathrm{W} \text { (water supply) } \\
\sigma_{W}(\text { variance in water supply }) \\
W_{0}(\text { Initial water supply })\end{array}$ & $\begin{array}{c}\mathrm{d} W=\sigma_{W} W \mathrm{~d} z \\
0.15 \\
50 \text { thousand cubic meter }\end{array}$ \\
\hline $\begin{array}{l}\text { w (amount of water purchased } 1000 \text { cubic meter) } \\
\text { I (investment in storage reservoir) } \\
\text { h (investment in efficient irrigation technology) }\end{array}$ & $\begin{array}{l}\text { choice variable } \\
\text { choice variable } \\
\text { choice variable }\end{array}$ \\
\hline
\end{tabular}

We also examined how the adoption rate of modern irrigation techniques will change with the change in water supply volatility. Results, as illustrated in Figure 3, show how aggregate investment in irrigation techniques changes with increase in variance of water. The result is consistent with the theoretical finding of a negative relationship between investment and the variance of water supply. However, we found that if risk aversion is high or inter temporal elasticity is low then higher variance or uncertainty will produce an increase in the certainty equivalent of the return to investment in efficient irrigation, and as a result farmers may invest more. But in such case, we found that the increase in variance of water must be sufficiently high for the aggregate investment to be higher. This result also justifies the historical patterns of modern irrigation technology adoption as evident from the studies of Shuck et. al (2005) [17] Zilberman et. al (1995) [5] and Caswel et. 


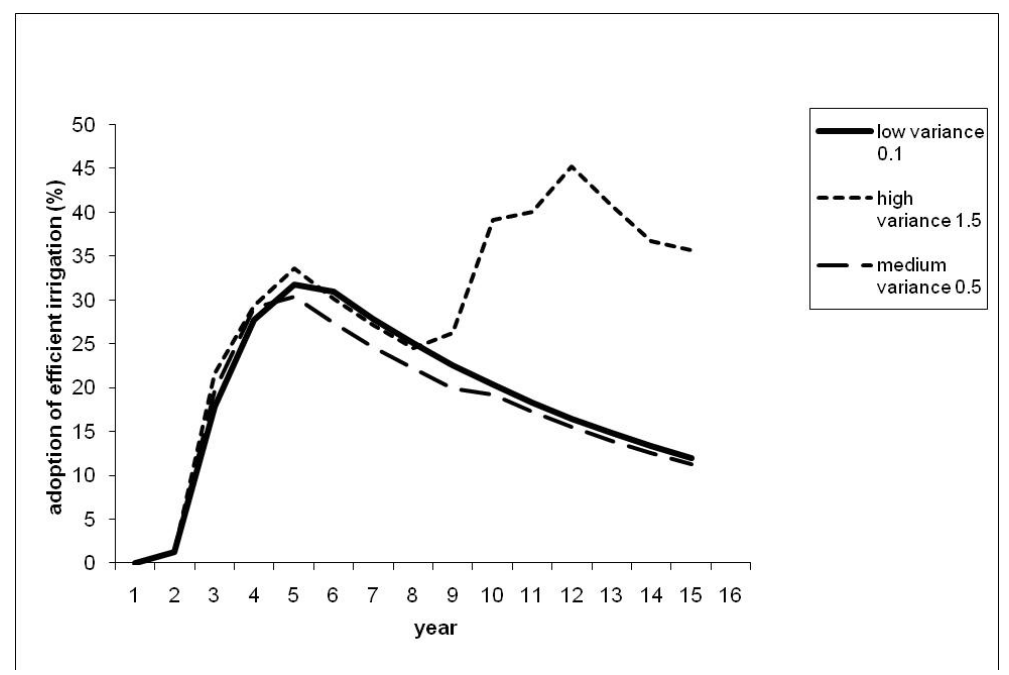

FiguRE 3. Adoption of efficient irrigation technologies under different levels of variance in water supply

al (1991) [12], which have shown that adoption of the drip irrigation increase dramatically when the frequency of droughts is very high.

\section{Conclusion}

Contrary to the prediction of economic theory that resource use efficiency improves with scarcity, water use is becoming less and less efficient even as water grows more scarce. Saleth and Dinar(2004) noted that the problem may lie in water sectoral policies, including the approach on which they are based and the framework within which they are formulated and implemented [13]. In many countries, water prices are fixed and determined administratively, reflecting neither supply cost nor the scarcity value. Moreover, when the scarcity value of water is increasing, it could be inappropriate to insulate the water economy from market forces. In this paper, we investigated how to get the water prices right so that it can induce the farmers to adopt efficient irrigation techniques. We explore whether increasing variance in water supply can induce the farmers to conserve water through the adoption of efficient irrigation methods.

We found that a flexible water price, which depends on stochastic water demand as well as aggregate demand, can increase the adoption rate of efficient irrigation techniques by more than 20 per cent for a risk averse farmer. 
We also found if farmers invest in water storage capacity then the value of efficient irrigation increases, and the rate of adoption will be higher. In our theoretical model, we found a complementarity relationship between investment in storage capacity and efficient irrigation techniques. The relationship becomes stronger with increasing variance in water supply. The relationship holds if the marginal benefit function is convex. In a situation with no option of storage capacity, we find that the value of the investment in efficient irrigation techniques will not be sufficient to guarantee higher investment under uncertainty. However, a risk averse farmer may invest more in efficient irrigation only if the variance in water supply is very high .

In sum, the finding of the paper is consistent with the general view that flexible water pricing is a valid alternative for increasing the efficiency of water usage. However, even a flexible water pricing cannot guarantee higher adoption of efficient irrigation technology under increasing variance of water supply. If farmers also have the option to invest in storage capacity, then the adoption rate will be significantly higher.

However, the majority of the farmers in transition and developing countries are resource poor small holders who may find it difficult economically to adopt efficient irrigation techniques. Hence the approach must be sensitive to match the farmers unique characteristics of low capital availability. Moreover, flexible water price also requires suitable institutional arrangements, for instance metering of water, for implementation as well as monitoring.It might lead to additional cost. Variation in water supply stemming from climate change may also induce the farmers to cultivate alternative crops that require less water or high valued crops to adopt efficient irrigation technologies. In the current paper, we have ignored cropping pattern change for analytical simplicity. Future work can focus on these aspect. 


\section{ApPENDix A}

Rearranging the first order condition, (2.11), we get $J_{p}=\frac{1}{k}\left[p-\frac{\partial B}{\partial w}\right]$.

Using Itô's Lemma and considering $J_{p}=X$ we get

$$
d X=X_{w} d w+1 / 2 X_{w w}(d w)^{2} .
$$

Considering that $w^{\star}=w(H, p, W)$ along the optimal path, using Itô's Lemma again,

$$
d w=\frac{\partial w}{\partial H} d H+\frac{\partial w}{\partial p} d p+\frac{\partial w}{\partial W} d W+\frac{1}{2} \frac{\partial^{2} w}{\partial W^{2}}(d W)^{2},
$$

and by substitution of $d H, d p, d W$ and $(d W)^{2}$,

$d w=\left(h-\delta_{H} H\right) \frac{\partial w}{\partial H} d t+k\left(\sum w-W\right) \frac{\partial w}{\partial p} d t+\sigma W \frac{\partial w}{\partial W} d z+\frac{1}{2} \sigma^{2} W^{2} \frac{\partial^{2} w}{\partial W^{2}} d t$.

The implied expression for $(d w)^{2}$ is greatly simplified by neglecting the terms of higher order in $d t$ as $d t$ goes to zero, so that we are left with $(d w)^{2}=\left(\frac{\partial w}{\partial W}\right)^{2} \sigma^{2} W^{2} d t$ where $(d z)^{2}=d t$.

Substituting, $(d w)^{2}=\left(\frac{\partial w}{\partial W}\right)^{2} \sigma^{2} W^{2} d t$ in (A-1) , applying the differential operator $\frac{1}{d t} E_{t}$ and considering $E_{t}(d z)=0$, we get

$$
1 / d t E_{t}(d X)=X_{w} 1 / d t E_{t}(d w)+\frac{1}{2} X_{w w}\left(\frac{\partial w}{\partial W}\right)^{2} \sigma^{2} W^{2} d t=w+r J_{p}
$$

At the long run equilibrium value, the expected change in the value of water consumption is zero and setting, $1 / d t E_{t}(d w)=0$ in $(\mathrm{A}-4)$, we obtain

$$
\frac{1}{2 k}\left(p_{w w}-B_{w w w}\right)\left(\frac{\partial w}{\partial W}\right)^{2} \sigma^{2} W^{2}=w+r J_{p} .
$$

\section{APPENDix B}

Substituting $\frac{\partial J_{p}}{\partial H}$ from (2.23), we get

$$
\begin{aligned}
& \frac{\partial J_{p}}{\partial H}-\frac{B_{w_{e} w_{e}}\left(r+\delta_{H}\right) c^{H} w}{\left[B_{w_{e}}\right]^{2}}= \\
& \quad \frac{r}{k}\left[p_{w_{e}} w-B_{w_{e} w_{e}} w_{e}-B_{w_{e}}\right]\left(e_{H}-e_{F}\right)-\frac{B_{w_{e} w_{e}}\left(r+\delta_{H}\right) c^{H} w}{\left[B_{w_{e}}\right]^{2}}
\end{aligned}
$$


As $p_{w_{e}}>0, B_{w_{e} w_{e}}<0$ and $B_{w_{e}}>0$, the above expression the only negative term is $\frac{r}{k} B_{w_{e}}\left(e_{H}-e_{F}\right)$, and the latter term will be dominated by the other terms due to the term $w$ and $w_{e}$.As a results $\frac{\partial J_{p}}{\partial H}-\frac{B_{w_{e} w_{e}}\left(r+\delta_{H}\right) c^{H} w}{\left[B_{w_{e}}\right]^{2}}$ will be positive .

\section{Appendix C}

Suppose $k J_{p}+(1-\beta) J_{S}=p-B_{w}=X$. From equation (A-1) and $(d w)^{2}=\left(\frac{\partial w}{\partial W}\right)^{2} \sigma^{2} W^{2} d t$, we have

$$
1 / d t E_{t}(d X)=X_{w} 1 / d t E_{t}(d w)+\frac{1}{2} X_{w w}\left(\frac{\partial w}{\partial W}\right)^{2} \sigma^{2} W^{2}
$$

setting, $1 / d t E_{t}(d w)=0$ and $p_{w w}=0$, we obtain

$$
1 / d t E_{t}(d X)=-\frac{1}{2}\left(B_{w w w}\right)\left(\frac{\partial w}{\partial W}\right)^{2} \sigma^{2} W^{2}
$$

If we take the differential operator to $X=k J_{p}+(1-\beta) J_{S}=p-B_{w}$, we have

$$
1 / d t E_{t}(d X)=k(1 / d t) E_{t}\left(d J_{p}\right)+(1-\beta) 1 / d t E_{t}\left(d J_{S}\right)
$$

Substituting (3.34)and (3.39) in (A-9), results in

$$
\begin{aligned}
1 / d t E_{t}(d X)=r k & J_{p}+r(1-\beta) J_{S}+k w+(1-\beta) \psi \\
= & r\left(k J_{p}+(1-\beta) J_{S}\right)+k w+(1-\beta) \psi \\
& =r\left(p-B_{w}\right)+k w+(1-\beta) \psi
\end{aligned}
$$

Hence from (A-8) and (A-10) we have

$$
r\left(p-B_{w}\right)+k w+(1-\beta) \psi=-\frac{1}{2}\left(B_{w w w}\right)\left(\frac{\partial w}{\partial W}\right)^{2} \sigma^{2} W^{2}
$$

\section{REFERENCES}

[1] Bates B.C., Z.W. Kundzewicz, S. Wu, and J.P. Palutikof. Climate change and water. technical paper of the intergovernmental panel on climate change. Technical report, IPCC Secretariat, Geneva, 210 pp, 2008.

[2] Fisher Anthony C and Santiago J. Rubio. Adjusting to climate change: Implications of increased variability and asymmetric adjustment costs for investment in water reserves. Journal of Environmental Economics and Management, 34(3):133-185, 1997.

[3] Shaliba B. C and D. B Bush. Water markets in theory and practice: Market Transfers, water Values, and Public Policy. Westview Press, Boulder Colorado, 1987. 
[4] Sekler David, Upali Amarsinghe, David Molden, R deSilva, and R Barker. World water demand and supply 1990-2025.-scenarios and issues. Technical report, IWMI Research Report 19, 1998.

[5] Zilberman David, A Dinar, N MacDougall, M Khanna, C Brown, and F Castilo. Individual and institutional responses to drought: The case of california's agriculture. Working paper, University of California Berkeley, 1995.

[6] Shah F, David Zilberman, and U Chakravorty. Technology adoption in the presence of an exhaustible resource:the case of groundwater extraction. American Journal of Agricultural Economics, 77:291-299, 1995.

[7] Harou Julien J, Manuel Pulido-Velazquez, David E. Rosenberg, Jay R. Lund Josu Medelln-Azuara, and Richard E. Howitt. Hydro-economic models: Concepts, design, applications, and future prospects. Journal of Hydrology, 375:627-643, 2009.

[8] Carey M Janis and David Zilberman. A model of investment under uncertainty: Modern irrigation technology and emerging markets in water. American Journal of Agricultural Economics, 84:171-183, 2002.

[9] Knapp K and L. Olson. The economics of conjunctive groundwater management with stochastic surface supplies. Journal of Environmental Economics and Management, 28:340-356, 1995.

[10] Sampath R. K. Issues in irrigation pricing in developing countries. World Developement, 20:967-977, 1992.

[11] Federick D Kenneth and David C Major. Climate Change and Water Resources, volume 2 of The Management of Water Resource. Edward Elgar, New York, 2002 .

[12] Caswell M. Irrigation Technology Adoption Decisions: Empirical Evidence. The Economics and Management of Water and Drainage in Agriculture. Kluwer Academic Press, Boston, 1991.

[13] Saleth Maria and Ariel Dinar. The Institutional Economics of water- A cross country analysis of institution and performance. Edward Elgar Massachusetts USA, 2004.

[14] Rosegrant Mark and R. S Meinzen-Dick. Water resources in the asia pacific region. Asia Pacific Economic Literature, 10:32-53, 1996.

[15] Ranjan Ram and Sanhita Athalye. Drought resilience in agriculture: The role of technological options, land use dynamics, and risk perception. Natural Resource Modelling, 22:437-462, 2009.

[16] Postel S. Pillars of Sand: Can the irrigation miracle last? WW Norton and Company, New York, 1999.

[17] E.C. Schuck, W.M. Frasier, R.S.Webb, L.J. Ellingson, and W.J. Umberger. Adoption of more technically e?cient system as a drought response. Water Resource Development, 21:651-652, 2005.

[18] Tsur Y and T. Graham-Tomasi. The buffer value of groundwater with stochastic surface water supplies. Journal of Environmental Economics and Management, 21:201-224, 1991. 